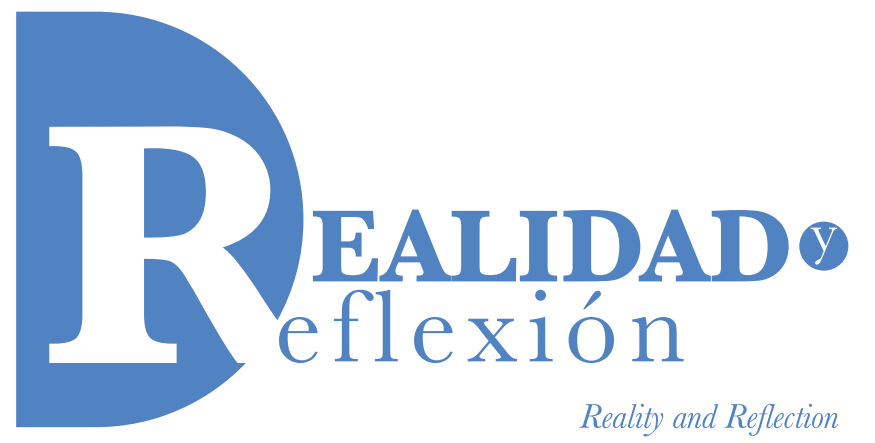

ISSN 1992-6510

e-ISSN 2520-9299

Año 18, N 47, San Salvador, El Salvador, Centroamérica. Revista Semestral Enero-Junio 2018

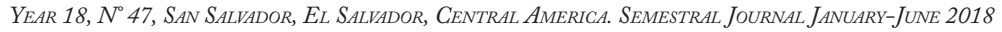

\title{
Financiamiento de la educación en El Salvador: un análisis más allá del porcentaje del PIB. Período 2000-2018
}

\section{Financing of education in El Salvador: an analysis beyond the GDP. Period 2000-2018}

\author{
Jeser C. Candray \\ Master en Educación en Ciencia y en Matemática por la Universidade Federal do Paraná (UFPR), \\ Investigador del Instituto de Ciencia, Tecnología e Innovación de la Universidad Francisco Gavidia (ICTI-UFG) \\ jcandray@ufg.edu.sv, jccandray@gmail.com \\ Recibido: 21 de mayo de 2018 \\ Aprobado: 1 de junio de 2018 \\ DOI: http://dx.doi.org/10.5377/ryr.v0i47.6281
}

\section{RESUMEN}

El objetivo de este artículo es actualizar algunos indicadores relacionados al financiamiento de la educación en El Salvador. Esta necesidad surge debido a que el Banco Central de Reserva de El Salvador presentó el año 2018 un nuevo Sistema de Cuentas Nacionales (SCN) que modificó la medición del Producto Interno Bruto (PIB) de El Salvador. Para tal situación se presenta en primer lugar los datos actualizados en porcentajes según el Presupuesto General de la Nación (PGN) y del PIB del presupuesto del Ministerio de Educación (MINED) desde el año 2000 hasta el año 2018; en segundo lugar, se presenta a mayor detalle los presupuestos del MINED de los años 2004, 2009, 2014 y 2018 con el objetivo de verificar su estructura de gastos; y por último, este artículo presenta los datos de inversión en educación según el PGN y PIB de la República de Costa Rica en los años 2005, 2010 y 2015 con el objetivo de traer otros datos que ayuden al entendimiento de ésta temática.

Palabras clave: Políticas educacionales, Financiamiento de la Educación, El Salvador.

\section{ABSTRACT}

The aim of this article is to update the indicators related to the financing of education in El Salvador. This need arises because the Central Reserve Bank of El Salvador presented in 2018 a new System of National Accounts (SNA) that modified the measurement of the Gross Domestic Product (GDP) of El Salvador. For this situation, the updated data is presented in percentages according to the General National Budget (PGN) and the GDP of the Ministry of Education budget (MINED) since 2000 to 2018; Secondly, the MINED budgets of 2004, 2009, 2014 and 2018 are presented in detail with the aim of verifying their expenditure structure; and finally, this article presents data on investment in education according to the GNP and GDP of the Republic of Costa Rica in the years 2005, 2010 and 2015 with the aim of bringing other data that help to understand this topic.

Keywords: Educational policies, financing of education, El Salvador. 


\section{Palabras iniciales}

Este artículo tiene como objetivo; en primer lugar, actualizar algunos indicadores que versan sobre el financiamiento de la educación en E1 Salvador. En el año 2018 el Banco Central de Reserva de El Salvador (BCR) publicó el nuevo Sistema de Cuentas Nacionales que ofrece datos interesantes sobre el valor del Producto Interno Bruto $\left(\mathrm{PIB}^{1}\right)$ que, en resumen, establece que la economía salvadoreña era más pequeña de lo que se estimaba (cerca de un 11\% menos en comparación del antiguo $\mathrm{SCN}$ ), este hecho afecta la medición de los macro-indicadores del país, entre ellos los relacionados a la Educación que son de interés en este artículo.

Ahora bien, ¿cómo afecta el nuevo PIB a la definición de indicadores vinculados al financiamiento de la educación del país? ¿Cómo quedan actualizados los datos de inversión en Educación en los últimos años? Para responder esta pregunta se presentan los indicadores sobre el presupuesto de Educación por gestión de Gobierno, es decir, los datos del quinquenio de Francisco Flores (1999-2004), Tony Saca (20042009), Mauricio Funes (2009-2014) y los datos actuales del gobierno de Salvador Sánchez Cerén (2014-2019). Se presenta a su vez, para cada gestión, una pequeña contextualización social, política y educativa del país así como los datos sobre la inversión en relación al PIB por año para los presupuestos votados y los presupuestos modificados. Esta sección cerrará haciendo una problematización sobre los inconvenientes que, a juicio del autor, conlleva condicionar la inversión

1 Datos del PIB tomados de: http://www.bcr.gob.sv/ bcrsite/?cdr=160\&lang=es. Consultado el día 20/04/2018. educativa del país al 6\% del PIB como muchas instituciones y medios de comunicación señalan como ideal.

Como segundo punto de este artículo, se presenta un análisis más detallado sobre la estructura de los presupuestos del Ministerio de Educación (MINED) a fin de interpretar cuales fueron las apuestas de los gobiernos. Para ello se analizan los presupuestos de salida aprobados por la Asamblea Legislativa (AL) de cada uno de las gestiones mencionadas cerrando esta sección con comentarios sobre los hallazgos.

Por último, en la tercera sección se trae a discusión, a manera de comparación, los datos sobre la inversión de educación en la República de Costa Rica, ¿por qué es importante traer esto a discusión ahora? El autor considera que importante aportar estos datos a modo de evitar comparaciones descontextualizadas que vienen ganando espacio en el país.

Sin más que agregar, se presentan los datos del financiamiento de la educación según el nuevo PIB de los gobiernos de Francisco Flores, Tony Saca, Mauricio Funes y Salvador Sánchez Cerén, respectivamente.

\section{Financiamiento de la Educación en E1 Salvador según nuevo PIB, período 2000-2018}

Antes de presentar los datos, es necesario hacer aclaraciones sobre los mismos y la forma en que serán presentados. En El Salvador, el período presidencial se inicia el primero de junio del año que se celebra la elección; es decir, que el primer presupuesto de la nueva gestión será el del siguiente año. Por ejemplo, la primera gestión 
que se analiza es la de Flores que comenzó y finalizó el primero de junio de 1999 y finalizó en 2004, por lo tanto, los presupuestos presentados a la Asamblea Legislativa durante su gestión fueron los ejercicios fiscales del año 2000, 2001, 2002, 2003 y 2004 y son estos los que mejor representan a la administración, esta es la razón por la cual se presentan los presupuestos votados. ${ }^{2}$ También se decidió presentar los datos de los presupuestos ejecutados ${ }^{3}$ que son las cifras que fueron llevadas a la práctica; ambos datos serán divididos por el PIB y constituirán la inversión en educación para cada año.

Tomando en cuenta lo anterior, a continuación, se presentan los datos de cada gestión.

\subsection{Francisco Flores (1999-2004)}

El presidente Francisco Flores gobernó el país desde el primero de junio de 1999 hasta el primero de junio de 2004. Llegó al poder bajo la bandera del partido Alianza Republicana Nacionalista (ARENA) siendo su tercer presidente consecutivo y el segundo electo desde la firma de los Acuerdos de Paz que pusieron fin a la guerra civil en 1992. En términos generales, su Gobierno se caracterizó por el impulso de una agenda económica neoliberal cuyas principales medidas económicas fueron la dolarización del país a partir del año 2001 y que aún está en vigencia, la venta de activos del Estado (como el caso de LaGeo)

2 Tomados de: http://www.transparenciafiscal.gob.sv/ptf/es/ PresupuestosPublicos/Presupuestosvotados/. Consultados el día 20/04/18.

3 Tomados de http://www.transparenciafiscal.gob.sv/ptf/es/ PresupuestosPublicos/PresupuestosEjecutados/. Consultado el día 20/04/2018. y el abandono de la agricultura en detrimento de la economía basada en bienes y servicios; otras medidas como la privatización del agua y de la salud fueron duramente rechazadas por huelgas y protestas que al final impidieron su aprobación. En la parte social destacó el auge de la inseguridad producto de las pandillas y cuyo plan para combatirlas fue un "Plan de Mano Dura" que quedó en medidas mediáticas como la redadas masivas en zonas populosas del país, otro punto a destacar fue el golpe de dos terremotos de gran magnitud en enero y febrero del año 2001 que causaron daños considerables y decenas de muertos. En la parte educativa destaca que al frente de la gestión del MINED hubo dos ministros: Lcda. Evelyn Jacir de Lovo (junio de 1999-agosto de 2002) y Rolando Marín (septiembre 2002-mayo 2004) cuyo principal proyecto educativo fue el denominado "Desafíos de la Educación en el Nuevo Milenio", que incluía una reforma a la Educación Media, además buscaba invertir en el mejoramiento de la infraestructura escolar, ampliar la cobertura a través de programas tales como: Escuela Saludable, Educación con Participación de la Comunidad (EDUCO), que era un programa con vistas a dar acceso a la educación en la zona rural del país y los programas que buscaban introducir las nuevas tecnologías tales como Radio Interactiva, Teleaprendizaje y los Centros de Recursos para Aprendizajes (CRA). (Ver Tabla n. $\left.{ }^{\circ} 1\right)$

Con esos datos, el presupuesto votado del MINED en relación al PIB (\% MINED/PIB $\mathrm{V})$, el presupuesto ejecutado del MINED en relación al PIB y con relación al PGN en el período de Francisco Flores es el siguiente: (Ver Tabla n. ${ }^{\circ}$ ) 
Tabla n. ${ }^{\circ} 1$

Inversión en educación en El Salvador: gestión Flores (1999-2004), datos en dólares de los Estados Unidos de América

\begin{tabular}{|c|c|c|c|c|c|}
\hline \multicolumn{5}{|c|}{ Francisco Flores } \\
\hline Dato/Año & $\mathbf{2 0 0 0}$ & $\mathbf{2 0 0 1}$ & $\mathbf{2 0 0 2}$ & $\mathbf{2 0 0 3}$ & $\mathbf{2 0 0 4}$ \\
\hline PIB & $\$ 11,784.93$ & $\$ 12,282.53$ & $\$ 12,664.19$ & $\$ 13,243.89$ & $\$ 13,724.81$ \\
\hline PGN-E & $\$ 2,072.50$ & $\$ 2,392.14$ & $\$ 3,342.64$ & $\$ 2,550.02$ & $\$ 2,806.12$ \\
\hline PE-MINED & $\$ 358.06$ & $\$ 472.32$ & $\$ 468.78$ & $\$ 466.33$ & $\$ 463.58$ \\
\hline PV-MINED & $\$ 384.93$ & $\$ 428.85$ & $\$ 471.16$ & $\$ 484.49$ & $\$ 470.50$ \\
\hline
\end{tabular}

Fuente: Elaboración propia con información tomada de Transparencia Fiscal Ministerio de Hacienda de El Salvador y Banco Central de Reserva de El Salvador.

Tabla n. ${ }^{\circ} 2$

Inversión en educación en El Salvador, en porcentajes del PIB y del PGN, gestión Flores (1999-2004).

\begin{tabular}{|c|c|c|c|c|c|}
\hline \multicolumn{7}{|c|}{ Francisco Flores } \\
\hline Dato/Año & $\mathbf{2 0 0 0}$ & $\mathbf{2 0 0 1}$ & $\mathbf{2 0 0 2}$ & $\mathbf{2 0 0 3}$ & $\mathbf{2 0 0 4}$ \\
\hline$\%$ MINED/PIB E & $3.04 \%$ & $3.85 \%$ & $3.70 \%$ & $3.52 \%$ & $3.38 \%$ \\
\hline$\%$ MINED/PGN E & $17.28 \%$ & $19.74 \%$ & $14.02 \%$ & $18.29 \%$ & $16.52 \%$ \\
\hline$\%$ MINED/PIB V & $3.27 \%$ & $3.49 \%$ & $3.72 \%$ & $3.66 \%$ & $3.43 \%$ \\
\hline
\end{tabular}

Fuente: Elaboración propia con información tomada de Transparencia Fiscal Ministerio de Hacienda de El Salvador y Banco Central de Reserva de El Salvador.

Los datos anteriores muestran que cuatro de los cinco presupuestos ejecutados del MINED fueron menores (según el PIB) a los que habían sido originalmente aprobados, lo que sugiere que en el transcurso del año el presupuesto del MINED fue recortado. En términos brutos, el presupuesto ejecutado

4 Los datos del PV-MINED del año 2000 y 2001 fueron transformados de Colones salvadoreños a dólares estadounidenses a razón de 8.75 que fue el cambio fijado para 2001. Los datos, en colones, para el PV-MINED del año 2000 y 2001 fueron: $3,368,145,585$ y $3,752,436,835$ respectivamente. del MINED en el quinquenio Flores pasó de $\$ 358$ millones en 2000 a $\$ 463$ millones en 2004; es decir, un aumento neto de $\$ 105$ millones, \$21 millones cada año. E1 año atípico fue el 2001 que refleja el momento de mayor inversión bruta y relativa según el PIB en el quinquenio Flores y esto puede explicarse debido a que fue a principio de ese año que sucedieron los dos terremotos que afectaron significativamente la infraestructura y que requirió, según el informe de labores del MINED del 2001-2002, de un refuerzo 
presupuestario de 56 millones de dólares para la reconstrucción (MINED, 2002).

Si verificamos datos del MINED en función del PGN, este estuvo dentro del rango de $14 \%$ al 20\%. El año con menos inversión en educación en relación al PGN fue el año posterior a los terremotos del año 2001 y según reflejan los datos del PGN, los presupuestos del Ministerio del Interior (Gobernación) y el de Obras Públicas (MOP) se dispararon para atender las tareas de reconstrucción. El resto de años mostró relativa estabilidad.

En resumen, el presupuesto votado en el quinquenio Flores pasó de 3.04\% del PIB en 2000 al 3.38\% del PIB en 2004, o sea, un aumento del $0.34 \%$ según el PIB en cinco años; el año de mayor inversión en educación según el PIB fue en 2002 con $3.85 \%$.

Analizados los datos de la gestión Flores, a continuación se presentan los datos de la gestión Saca.

\subsection{Elías Antonio Saca (2004-2009)}

El presidente Elías Antonio Saca, conocido popularmente como Tony Saca, sucedió en la presidencia de la república a Francisco Flores desde el primero de junio de 2004 al primero de junio de 2009, siendo el cuarto presidente electo bajo la bandera de ARENA. Su Gobierno destacó por dar una mayor inversión en lo social gracias a una reforma fiscal que incrementó los ingresos del Estado, creando programas como "Red Solidaria", "Fosalud"; sin embargo, el último año y medio de su gestión fue marcada por la desaceleración económica mundial que también afectó al país. En lo social destaca la profundización del problema de las pandillas para la cual rediseñó un plan al que llamó "Súper Mano Dura", reestableciendo el extinto Ministerio de Seguridad. En el área educativa, el MINED tuvo una única titular durante toda la gestión: la Lcda. Darlyn Meza. Las principales apuestas educativas en ese período fueron el Plan 2021, la actualización de los programas de estudio de Educación Básica y Media, el bachillerato gratuito, el programa EDÚCAME (bachillerato virtual) y la consolidación del programa de educación para comunidades rurales EDUCO así como la apuesta a los institutos tecnológicos conocidos como MEGATEC (MINED, 2005).

En lo referente a los datos de inversión en educación de la gestión Saca, se hace el mismo ejercicio anterior y se presenta el valor del PIB, el Presupuesto General de la Nación ejecutado (PGN-E) y el Presupuesto Ejecutado y Votado del MINED (PE-MINED) y (PV-MINED), respectivamente. Los datos son los siguientes: Ver Tabla n. ${ }^{\circ}$ )

Es decir que, considerando estos datos, el presupuesto votado del MINED en relación al PIB (\% MINED/PIB V), el presupuesto ejecutado del MINED en relación al PIB y con relación al PGN en el gobierno Saca fueron: (Ver Tabla n. ${ }^{\circ}$ )

La presidencia Saca presenta muchos datos interesantes que, si no son analizados bajo el contexto que sucedieron, pueden generar conclusiones alejadas de la realidad. Por ejemplo, en términos brutos el presupuesto del MINED en ese período pasó de \$501 millones en 2005 a $\$ 756$ millones en 2009; es decir, que 
Tabla n. ${ }^{\circ} 3$

Inversión en educación en El Salvador: gestión Saca (2004-2009), datos en dólares de los Estados Unidos de América.

\begin{tabular}{|c|c|c|c|c|c|}
\hline \multicolumn{7}{|c|}{ Tony Saca } \\
\hline Dato/Año & $\mathbf{2 0 0 5}$ & $\mathbf{2 0 0 6}$ & $\mathbf{2 0 0 7}$ & $\mathbf{2 0 0 8}$ & $\mathbf{2 0 0 9}$ \\
\hline PIB & $\$ 14,698.00$ & $\$ 15,999.89$ & $\$ 17,011.75$ & $\$ 17,986.89$ & $\$ 17,601.62$ \\
\hline PGN-E & $\$ 3,132.13$ & $\$ 3,634.48$ & $\$ 3,258.19$ & $\$ 3,624.08$ & $\$ 4,827.13$ \\
\hline PE-MINED & $\$ 501.33$ & $\$ 526.06$ & $\$ 575.14$ & $\$ 632.24$ & $\$ 756.22$ \\
\hline PV-MINED & $\$ 483.44$ & $\$ 510.75$ & $\$ 526.65$ & $\$ 635.00$ & $\$ 702.87$ \\
\hline
\end{tabular}

Fuente: Elaboración propia con información tomada de Transparencia Fiscal Ministerio de Hacienda de El Salvador y Banco Central de Reserva de El Salvador.

Tabla n. ${ }^{\circ} 4$

Inversión en educación en El Salvador, en porcentajes del PIB y del PGN, gestión Saca (1999-2004).

\begin{tabular}{|c|c|c|c|c|c|}
\hline \multicolumn{7}{|c|}{ Tony Saca } \\
\hline Dato/Año & $\mathbf{2 0 0 5}$ & $\mathbf{2 0 0 6}$ & $\mathbf{2 0 0 7}$ & $\mathbf{2 0 0 8}$ & $\mathbf{2 0 0 9}$ \\
\hline$\%$ MINED/PIB E & $3.41 \%$ & $3.29 \%$ & $3.38 \%$ & $3.52 \%$ & $4.30 \%$ \\
\hline$\%$ MINED/PGN E & $16.01 \%$ & $14.47 \%$ & $17.65 \%$ & $17.45 \%$ & $15.67 \%$ \\
\hline$\%$ MINED/PIB V & $3.29 \%$ & $3.19 \%$ & $3.10 \%$ & $3.53 \%$ & $3.99 \%$ \\
\hline
\end{tabular}

Fuente: Elaboración propia con información tomada de Transparencia Fiscal Ministerio de Hacienda de El Salvador y Banco Central de Reserva de El Salvador.

aumentó \$255 millones en ese período a razón de \$51 millones cada año, un 2.5\% mayor que el crecimiento en la gestión Flores. Una explicación a este dato puede encontrarse, como se mencionó con anterioridad, en la reforma fiscal impulsada en 2004 que buscó reducir la evasión y elusión de impuestos y que aumentó la capacidad de inversión del Estado. Contrario a lo verificado en la gestión Flores, vemos que cuatro de los cinco presupuestos ejecutados del MINED crecieron en relación al presupuesto votado.
El gasto en educación según el PIB y según el PGN muestra otra lectura a estos datos y es que si comparamos estos números en bruto en relación al PIB, el crecimiento en la inversión en educación es menos pronunciado de lo que parecía. El presupuesto ejecutado del MINED, según el PIB, pasó de $3.41 \%$ en 2005 a $4.30 \%$ en 2009 , un crecimiento de casi $0.9 \%$ del PIB un dato casi tres veces mayor al compararlo con la gestión anterior. Sin embargo, aquí es importante contextualizar estos datos, en especial el valor del año 2009 que fue de $4.3 \%$, si excluimos este dato del quinquenio 
vemos que el porcentaje de inversión en educación ronda entre el 3.29\% y 3.52\%, entonces, ¿Qué pasó en 2009? Hay varios elementos, primero es que en el año 2009 comienzan a sentirse los efectos de la crisis financiera de finales de 2008 que afectó a todo el mundo y que provocaron un decrecimiento del PIB para el 2009. El segundo elemento es que, y este es interno, el año 2009 se dio una elección presidencial que culminaría con la pérdida del Ejecutivo que ostentó por 20 años el partido ARENA. En este contexto electoral, en la cual el presidente Saca participó activamente, el Ejecutivo en lugar de hacer ajustes fiscales que pudieran afectar aún más las posibilidades de triunfo del partido ARENA (el candidato oficial siempre estuvo abajo en las encuestas frente al candidato opositor), decidió mantener los gastos del Estado lo que llevó al gobierno Saca, una vez ARENA perdió el Ejecutivo, a solicitar un préstamo de más de $\$ 1,200$ millones de dólares para corregir el déficit fiscal que rondaba casi el $5 \%$ del PIB. En términos educativos este dato del 4.30\% del PIB también encuentra algunas explicaciones y es que este año entró en vigencia la gratuidad del Bachillerato y el nuevo Gobierno impulsó su medida de entrega de útiles, zapatos y uniformes para los estudiantes de las escuelas públicas que fue financiado con un refuerzo presupuestario de 56 millones a finales de ese año (MINED, 2010).

El gasto en educación con relación al PGN fue relativamente estable en esta gestión, rondando entre el $14.47 \%$ y el $17.65 \%$. En resumen, este quinquenio mostró aumentos considerables en términos brutos al presupuesto de Educación, con un aumento de $\$ 51$ millones en promedio cada año y presentó su punto máximo en 2009 cuando alcanzó el 4.3\%, según el PIB.
A continuación se presentan los datos del quinquenio Funes.

\subsection{Mauricio Funes (2009-2014)}

Luego de veinte años de gobiernos consecutivos del partido de derecha ARENA, llega al mando del ejecutivo el primer presidente de la exguerrilla salvadoreña, el Frente Farabundo Martí para la Liberación Nacional (FMLN), experiodista Mauricio Funes quien gobernó El Salvador desde el primero de junio de 2009 al primero de junio de 2014. Dentro de la administración Funes destaca la creación del Plan Anticrisis cuyo objetivo era reactivar la economía luego de la crisis financiera mundial de 2008, una segunda reforma fiscal que elevó la carga tributaria del país, la creación de entidades de transparencia y el mantenimiento de programas sociales de la gestión Saca como Red Solidaria, entrega de uniformes, zapatos y útiles escolares a los estudiantes de educación básica de la red pública así como de los programas "Vaso de leche" y "Alimentación escolar”, entre otros.

Sobre el manejo de la situación de inseguridad destaca un controvertido plan llamado popularmente como la "tregua entre pandillas" que redujo considerablemente los índices de homicidios en el país y que al principio contó con el apoyo de la OEA y la iglesia católica, pero con el tiempo fue abandonado generando una nueva alza de los crímenes. En el plano educativo, la gestión Funes contó con dos ministros de Educación Ad-Honorem: el vicepresidente de la república, Salvador Sánchez Cerén (junio 2009-junio 2012) y Francis H. Hasbún (julio 2012-junio 2014). Dentro de los principales hechos relacionados a la educación 
en la gestión Funes destacan la eliminación del programa EDUCO que supuso pasar todos los contratos de profesores al sistema único; la creación de las Escuelas de Tiempo Pleno; la reformulación y ampliación de los planes de estudios de las carreras de profesorado y el Plan Social Educativo "Vamos a la escuela".

A continuación presentamos, cómo se hizo anteriormente, los datos totales del PIB, el Presupuesto General de la Nación y el presupuesto votado y ejecutado del Ministerio de Educación de este quinquenio. (Ver Tabla n. $^{\circ}$ )

Con esos datos, el presupuesto votado del MINED en relación al PIB (\% MINED/PIB $\mathrm{V})$, el presupuesto ejecutado del MINED en relación al PIB y con relación al PGN en la administración Funes fue el siguiente: (Ver Tabla n. ${ }^{\circ}$ )

Analizando en primer lugar los datos brutos del MINED en la gestión Funes se constata que el presupuesto pasó de $\$ 687$ millones en 2010 a $\$ 874$ millones; es decir, casi $\$ 190$ millones de dólares con un aumento, en promedio de $\$ 38$ millones cada año. Este crecimiento del presupuesto del MINED también podría tener su explicación en el aumento de la recaudación fiscal del Gobierno gracias a la reforma fiscal llevada por partes entre 2009 y 2012. Con relación a la variación entre el presupuesto votado y ejecutado es verificable que sufrió pocas modificaciones (salvo 2011 que aumentó considerablemente) variando entre tres y cinco millones más o menos.

Si revisamos los datos del presupuesto ejecutado del MINED con relación al PIB, estos destacan por una estabilidad en la inversión ya que va del $3.73 \%$ en 2010 al $3.87 \%$ en 2014 , o sea, refleja un crecimiento "modesto" de $0.15 \%$ aproximadamente durante el quinquenio Funes. El año de mayor inversión en educación según el PIB en este período fue el 2013 con un 3.91\%, el más bajo fue el 2010 con $3.73 \%$. El presupuesto del MINED según porcentajes del PGN es mucho más volátil con datos que van del $15.25 \%$ al $19 \%$.

En resumen podríamos decir que el quinquenio Funes fue un período de estabilidad y estancamiento en la inversión pública en educación. Estabilidad porque el porcentaje se mantuvo en números relativamente mayores a los quinquenios anteriores y de estancamiento porque no pudo superar más allá del $0.2 \%$ en todo su período.

\subsection{Salvador Sánchez Cerén (2014-2019)}

El primero de junio de 2014 tomó posesión por primera vez como presidente de El Salvador un excomandante guerrillero, el profesor Salvador Sánchez Cerén y es el segundo presidente del partido FMLN. Su gestión al frente del país destaca por llevar el programa de uniformes, zapatos y útiles escolares hasta bachillerato, el aumento considerable del salario mínimo y el mantenimiento de algunos programas sociales de administraciones anteriores; sin embargo, este período presidencial resalta en la parte negativa por los graves problemas fiscales que llevaron al país a un default en 2017 y con ello una fuerte contención del gasto público, la aprobación de una reforma al sistema privado de pensiones que aumentó la cotización de los empleadores y empleados y una agudización de la crisis de seguridad que llevó los índices 
Tabla n. ${ }^{\circ} 5$

Inversión en educación en El Salvador: gestión Funes (2009-2014), datos en dólares de los Estados Unidos de América.

\begin{tabular}{|c|c|c|c|c|c|}
\hline \multicolumn{7}{|c|}{ Mauricio Funes } \\
\hline Dato/Año & $\mathbf{2 0 1 0}$ & $\mathbf{2 0 1 1}$ & $\mathbf{2 0 1 2}$ & $\mathbf{2 0 1 3}$ & $\mathbf{2 0 1 4}$ \\
\hline PIB & $\$ 18,447.92$ & $\$ 20,283.78$ & $\$ 21,386.15$ & $\$ 21,977.40$ & $\$ 22,585.84$ \\
\hline PGN-E & $\$ 3,995.47$ & $\$ 4,863.54$ & $\$ 4,341.54$ & $\$ 4,625.92$ & $\$ 5,741.87$ \\
\hline PE-MINED & $\$ 687.81$ & $\$ 763.99$ & $\$ 823.18$ & $\$ 859.15$ & $\$ 874.91$ \\
\hline PV-MINED & $\$ 671.45$ & $\$ 706.99$ & $\$ 827.71$ & $\$ 863.95$ & $\$ 884.93$ \\
\hline
\end{tabular}

Fuente: Elaboración propia con información tomada de Transparencia Fiscal, Ministerio de Hacienda de El Salvador y Banco Central de Reserva de El Salvador.

Tabla n. ${ }^{\circ} 6$

Inversión en educación en El Salvador, en porcentajes del PIB y del PGN, gestión Funes (2009-2014).

\begin{tabular}{|c|c|c|c|c|c|}
\hline \multicolumn{7}{|c|}{ Mauricio Funes } \\
\hline Dato/Año & $\mathbf{2 0 1 0}$ & $\mathbf{2 0 1 1}$ & $\mathbf{2 0 1 2}$ & $\mathbf{2 0 1 3}$ & $\mathbf{2 0 1 4}$ \\
\hline$\%$ MINED/PIB E & $3.73 \%$ & $3.77 \%$ & $3.85 \%$ & $3.91 \%$ & $3.87 \%$ \\
\hline$\%$ MINED/PGN E & $17.21 \%$ & $15.71 \%$ & $18.96 \%$ & $18.57 \%$ & $15.24 \%$ \\
\hline$\%$ MINED/PIB V & $3.64 \%$ & $3.49 \%$ & $3.87 \%$ & $3.93 \%$ & $3.92 \%$ \\
\hline
\end{tabular}

Fuente: Elaboración propia con información tomada de Transparencia Fiscal Ministerio de Hacienda de El Salvador y Banco Central de Reserva de E1 Salvador.

de homicidios a niveles históricos. Como respuesta a esta situación de inseguridad, fueron aprobadas unas medidas extraordinarias que endurecieron las condiciones penitenciarias de los principales líderes de las pandillas, así como una mayor libertad a los policías para el uso de la fuerza. Estas medidas fueron denunciadas por organismos nacionales e internacionales como "atentatorias a los derechos humanos". En el plano educativo, el Ing. Carlos Canjura ha ejercido como Ministro de Educación en todo el período, por lo menos hasta mayo de 2018 y cuyos principales programas educativos fueron la continuidad del Plan Social Educativo "Vamos a la escuela", el inicio de la oferta de la educación inicial, el programa "Un niño, una niña y una computadora", la creación de la Universidad en Línea, el Plan Nacional de Formación Docente, la creación del Instituto de Formación Docente (INFOD), aumentos significativos al salario docente y el Plan Nacional de Alfabetización.

Los datos sobre el PIB de este período, la inversión en educación, presupuesto votado $\mathrm{y}$ 
ejecutado del MINED durante el Gobierno de Salvador Sánchez Cerén son los siguientes: (Ver Tabla n. ${ }^{\circ}$ )

Con esos datos, el presupuesto votado del MINED en relación al PIB (\% MINED/PIB $\mathrm{V})$, el presupuesto ejecutado del MINED en relación al PIB y con relación al PGN en el período de Salvador Sánchez Cerén son los siguientes: (Ver Tabla n. ${ }^{\circ}$ )

Dado que este período presidencial está en funciones, sólo se discute sobre los tres de los cinco presupuestos, del 2015-2017 y las proyecciones de 2018. Dada esa aclaración, se verifica que los tres presupuestos ejecutados son mayores a los presupuestos votados y todos arriba de $\$ 925$ millones y mayores a los presupuestos del año inmediato anterior. Sin embargo, el presupuesto para 2018 sí presenta un descenso de alrededor de 15 millones respecto al presupuesto de 2017. $\mathrm{Si}$ se analizan los datos del presupuesto del MINED como porcentajes del PIB, la lectura es diferente y se puede verificar que la inversión pública en educación está disminuyendo desde el prometedor $4.0 \%$ de 2015 a un $3.85 \%$ en 2017. Comparativamente con los otros quinquenios, es evidente que hay una mayor inversión pública en este período; sin embargo, ¿Qué explicación podríamos dar a este retroceso en la inversión? Tres datos, que no son únicos ni exhaustivos, se pueden aportar para la discusión. Primero, el crecimiento del presupuesto de otras áreas como la seguridad pública, dada la crisis de inseguridad antes expuesta, un segundo elemento resulta de la crisis fiscal del país que lo llevó a un default en 2017 producto del pago de la deuda que rondó el 20\% del PGN y aunado a la deuda de las pensiones, hicieron que el gasto social del
GOES en términos del PIB se desplomase. Por último, se trae como referencia una sentencia de la Sala de lo Constitucional que obliga al GOES a presentar los presupuestos a partir de 2018 con todos los gastos, incluida la deuda, contrario a lo acostumbrado a años anteriores.

El presupuesto del MINED, en términos brutos pasó de $\$ 926$ millones en 2015 a $\$ 940$ millones en 2018, con un crecimiento de $\$ 14$ millones, menos de cinco millones cada año. En términos porcentuales del PGN, mostraron estabilidad cercana al 19\%, salvo la proyección del 2018 que lo reduce al $17.20 \%$.

Concluida la presentación de los datos del financiamiento de educación en E1 Salvador en los últimos períodos presidenciales, se procede en la siguiente sección a discutir en rasgos generales los datos arrojados.

\subsection{Resumen de los últimos cuatro períodos presidenciales (2000-2018)}

Los datos de inversión en educación en los quinquenios de F. Flores, T. Saca, M. Funes y el preliminar de la gestión Cerén son los siguientes: (Ver Tabla n. ${ }^{\circ}$ 9)

Si se analiza el crecimiento en bruto del presupuesto ejecutado del MINED se verifica que el período con mayor crecimiento anual fue en el quinquenio Saca con un promedio de $\$ 51$ millones y el período con menor crecimiento es el de Salvador Sánchez Cerén que es menor a \$5 millones. Sin embargo, en términos generales, los datos reflejan un crecimiento muy lento de la inversión pública en educación durante estos 18 años. Esos años le ha tomado al Estado 
Tabla n. ${ }^{\circ} 7$

Inversión en educación en El Salvador: gestión Cerén (2014-2017), datos en dólares de los Estados Unidos de América.

\begin{tabular}{|c|c|c|c|c|}
\hline \multicolumn{5}{|c|}{ Salvador Sánchez Cerén } \\
\hline Dato/Año & $\mathbf{2 0 1 5}$ & $\mathbf{2 0 1 6}$ & $\mathbf{2 0 1 7}$ & $\mathbf{2 0 1 8 5}$ \\
\hline PIB & $\$ 23,166.03$ & $\$ 23,912.23$ & $\$ 24,805.44$ & $\$ 25,425.58$ \\
\hline PGN-E & $\$ 4,775.89$ & $\$ 4,804.93$ & $\$ 4,957.83$ & $\$ 5,467.49$ \\
\hline PE-MINED & $\$ 926.64$ & $\$ 943.06$ & $\$ 955.38$ & $\$ 940.43$ \\
\hline PV-MINED & $\$ 917.68$ & $\$ 942.21$ & $\$ 944.36$ & $\$ 940.43$ \\
\hline
\end{tabular}

Fuente: Elaboración propia con información tomada de Transparencia Fiscal, Ministerio de Hacienda de El Salvador y Banco Central de Reserva de El Salvador.

Tabla n. ${ }^{\circ} 8$

Inversión en educación en El Salvador, en porcentajes del PIB y del PGN, gestión Cerén (2014-2017).

\begin{tabular}{|c|c|c|c|c|}
\hline \multicolumn{5}{|c|}{ Salvador Sánchez Cerén } \\
\hline Dato/Año & $\mathbf{2 0 1 5}$ & $\mathbf{2 0 1 6}$ & $\mathbf{2 0 1 7}$ & $\mathbf{2 0 1 8}^{\mathbf{6}}$ \\
\hline$\%$ MINED/PIB E & $4.00 \%$ & $3.94 \%$ & $3.85 \%$ & $3.70 \%$ \\
\hline$\%$ MINED/PGN E & $19.40 \%$ & $19.63 \%$ & $19.27 \%$ & $17.20 \%$ \\
\hline$\%$ MINED/PIB V & $3.96 \%$ & $3.94 \%$ & $3.81 \%$ & $3.70 \%$ \\
\hline
\end{tabular}

Fuente: Elaboración propia con información tomada de Transparencia Fiscal Ministerio de Hacienda de El Salvador y Banco Central de Reserva de El Salvador.

subir $0.5 \%$ del PIB al presupuesto educación. Los datos entre quinquenios son tan bajos que no permiten diferenciar el nivel de interés o prioridad en todos los Gobiernos estudiados.

Además, al revisar los datos de cada uno de los

5 Datos del PIB 2018 son estimaciones. Aún no hay datos del presupuesto ejecutado.

6 Dicha Sala también tomó mucho protagonismo al declarar "inconstitucional" algunos impuestos aprobados por el Ejecutivo y el Legislativo que llevaron, según funcionarios del GOES, a asfixiar las finanzas del Estado. presupuestos del MINED se pudo verificar que algunas partidas que lo componían distaban mucho de los objetivos y fines de la educación, es así que en la siguiente sección se discute a profundidad el tema.

\section{III. ¿En realidad, se invierte ese porcentaje en educación?}

Como se dijo anteriormente, otro aspecto que motivó a elaborar este artículo surge de la necesidad de revisar la estructura y la 
Tabla n. ${ }^{\circ} 9$

Inversión en educación en El Salvador, promedios de la gestión Flores, Saca, Funes y la preeliminar de Sánchez Cerén. Período (2000-2017).

\begin{tabular}{|l|c|c|c|c|}
\hline & Francisco Flores & Tony Saca & Mauricio Funes & Salvador Sánchez Cerén $^{7}$ \\
\hline MINED/PIB E & $3.49 \%$ & $3.56 \%$ & $3.82 \%$ & $3.93 \%$ \\
\hline MINED/PGN E & $17.06 \%$ & $16.21 \%$ & $17.07 \%$ & $19.43 \%$ \\
\hline MINED/PIB V & $3.51 \%$ & $3.41 \%$ & $3.76 \%$ & $3.90 \%$ \\
\hline
\end{tabular}

Nota: Elaboración propia. Los porcentajes fueron calculados aplicando la media geométrica.

repartición del presupuesto del Ministerio de Educación (MINED) en cuyas asignaciones presupuestarias se encuentran partidas distantes de los fines de la educación del país y que, de alguna manera, distorsionan el dato real en inversión pública en educación. Para ello se presenta a continuación cuadros más detallados sobre las principales partidas que constituyeron los presupuestos del MINED votados del último año de gestión de las administraciones Flores (2004), Saca (2009), Funes (2014) y el último presentado por Cerén (2018).

\section{Cuadro n. ${ }^{\circ} 1$}

PRESUPUESTO VOTADO MINED 2004. ADMINISTRACIÓN FLORES (1999-2004). Datos en dólares de los Estados Unidos de América.

\begin{tabular}{|c|c|c|c|c|}
\hline Categoría & Presupuesto MINED 2004 & Cantidad & \multicolumn{2}{|c|}{$\begin{array}{c}\text { Porcentaje según presupuesto } \\
\text { MINED }\end{array}$} \\
\hline \multirow{4}{*}{$\begin{array}{l}\text { Administración } \\
\text { Central }\end{array}$} & Dirección y administración & $\$ 17,878,975$ & $3.80 \%$ & \multirow[t]{4}{*}{$21.09 \%$} \\
\hline & Gestión Educativa & $\$ 9,766,580$ & $2.08 \%$ & \\
\hline & Reforma/Tecnología & $\$ 70,528,880$ & $14.99 \%$ & \\
\hline & Caja Mutual & $\$ 1,051,220$ & $0.22 \%$ & \\
\hline \multirow{3}{*}{$\begin{array}{l}\text { Educación pre- } \\
\text { universitaria }\end{array}$} & Educación Inicial/ Parvularia & $\$ 33,215,415$ & $7.06 \%$ & \multirow[t]{4}{*}{$67.55 \%$} \\
\hline & Educación Básica & $\$ 251,660,210$ & $53.49 \%$ & \\
\hline & Educación Media & $\$ 28,998,270$ & $6.16 \%$ & \\
\hline EJA & Educación Jóvenes y Adultos & $\$ 3,969,555$ & $0.84 \%$ & \\
\hline \multirow{3}{*}{$\begin{array}{l}\text { Educación Superior } \\
\text { Pública }\end{array}$} & UES & $\$ 35,385,745$ & $7.52 \%$ & \multirow[t]{3}{*}{$7.59 \%$} \\
\hline & UES (Becas) & $\$ 205,715$ & $0.04 \%$ & \\
\hline & Instituto Educación (UES) & $\$ 114,290$ & $0.02 \%$ & \\
\hline
\end{tabular}

7 Media geométrica de los años 2015, 2016 y 2017. 


\begin{tabular}{|c|c|c|c|c|}
\hline \multirow{2}{*}{ Categoría } & Presupuesto MINED 2004 & Cantidad & \multicolumn{2}{|c|}{$\begin{array}{c}\text { Porcentaje según presupuesto } \\
\text { MINED }\end{array}$} \\
\hline \multirow{2}{*}{ Otros } & Subsidios instituciones privadas & $\$ 3,285,785$ & $0.70 \%$ & $1.06 \%$ \\
\cline { 2 - 5 } & FEDEFUT & $\$ 1,700,000$ & $0.36 \%$ & $2.71 \%$ \\
\hline \multirow{2}{*}{ Cultura } & CONCULTURA & $\$ 11,830,000$ & $2.51 \%$ & $0.19 \%$ \\
\cline { 2 - 5 } & Infraestructura Cultural & $\$ 907,150$ & $\mathbf{1 0 0 \%}$ & $\mathbf{1 0 0 \%}$ \\
\hline
\end{tabular}

Fuente: Elaboración propia. Portal de Transparencia del Ministerio de Hacienda (MH) de El Salvador.

Los presupuestos de Educación en la administración Flores son los últimos en hacer énfasis en la Reforma Educativa impulsada en los años noventa. El mayor gasto se encuentra asociado a la inversión en Educación Básica (53.49\%) con datos en inversión aún muy bajos en Educación Parvularia (Inicial aún no existía) y Educación Media con porcentajes menores al 7\%. En el plano de la Educación Superior Pública la UES, única universidad pública del país, su presupuesto rondó el 7.6\%. Llama la atención que en este quinquenio la Federación Salvadoreña de Fútbol obtuvo casi un 0.4\% y el presupuesto cultural rondó el $2.7 \%$. En total se puede decir que cerca de un $3.8 \%$ del presupuesto no correspondía a los fines del mismo.

Otro dato a relucir es que la partida destinada a remuneraciones constituye un 58\% del presupuesto del MINED siendo el salario docente el de mayor participación con una cifra un poco menor al $37 \%$ del presupuesto del MINED (ver ANEXO).

A continuación se presentan los datos del último presupuesto votado dentro de la administración Saca.

\section{Cuadro n. ${ }^{\circ} 2$}

PRESUPUESTO VOTADO MINED 2009. ADMINISTRACIÓN SACA (2004-2009). Datos en dólares de los Estados Unidos de América.

\begin{tabular}{|c|c|c|c|}
\hline & Presupuesto MINED 2009 & Cantidad & \multicolumn{2}{c|}{$\%$} \\
\hline \multirow{2}{*}{$\begin{array}{c}\text { Administración } \\
\text { Central }\end{array}$} & Dirección y administración & $\$ 26,377,050$ & $3.75 \%$ \\
\cline { 2 - 4 } & $\begin{array}{c}\text { Competitividad/Innovación/ } \\
\text { Infraestructura }\end{array}$ & $\$ 6,267,565$ & $0.89 \%$ \\
\cline { 2 - 4 } & Calidad/Tecnología & $\$ 13,050,200$ & $1.86 \%$ \\
\cline { 2 - 4 } & Plan 2021 & $\$ 60,069,285$ & $8.55 \%$ \\
\cline { 2 - 4 } & Caja Mutual & $\$ 1,051,220$ & $0.15 \%$ \\
\hline \multirow{2}{*}{\begin{tabular}{c} 
Educación pre- \\
\cline { 2 - 4 }
\end{tabular}} & Educación Inicial/Parvularia & $\$ 53,073,685$ & $7.55 \%$ \\
\cline { 2 - 4 } & Educación Básica & $\$ 378,354,835$ & $53.83 \%$ \\
\hline \multirow{2}{*}{ EJA } & Educación Media & $\$ 50,465,335$ & $7.18 \%$ \\
\hline
\end{tabular}




\begin{tabular}{|c|c|c|c|c|}
\hline & Presupuesto MINED 2009 & Cantidad & \multicolumn{2}{|c|}{$\%$} \\
\hline \multirow{2}{*}{$\begin{array}{l}\text { Educación Superior } \\
\text { Pública }\end{array}$} & UES & $\$ 55,029,910$ & $7.83 \%$ & \multirow[t]{2}{*}{$7.86 \%$} \\
\hline & UES (BECAS) & $\$ 205,715$ & $0.03 \%$ & \\
\hline \multirow[t]{5}{*}{ Otro } & $\begin{array}{l}\text { Subsidios instituciones privadas } \\
\text { (Fundaciones) }\end{array}$ & $\$ 16,415,485$ & $2.34 \%$ & \multirow[t]{5}{*}{$7.29 \%$} \\
\hline & $\begin{array}{c}\text { Otras entidades/Instituciones } \\
\text { Adscritas }\end{array}$ & $\$ 6,450,715$ & $0.92 \%$ & \\
\hline & ISNA & $\$ 13,798,370$ & $1.98 \%$ & \\
\hline & Dirección Nacional de Juventud & $\$ 941,770$ & $0.09 \%$ & \\
\hline & Canal 10 & $\$ 2,003,085$ & $1.96 \%$ & \\
\hline \multirow[t]{3}{*}{ Cultura } & CONCULTURA & $\$ 13,917,330$ & $0.13 \%$ & \multirow[t]{2}{*}{$0.42 \%$} \\
\hline & Infraestructura Cultural & $\$ 650,000$ & $0.28 \%$ & \\
\hline & Total & $\$ 702,874,705$ & $100 \%$ & $100 \%$ \\
\hline
\end{tabular}

Fuente: Elaboración propia. Datos tomados del Portal de Transparencia del Ministerio de Hacienda (MH) de El Salvador. Disponible en: http://www.transparenciafiscal.gob.sv/ptf/es/ PresupuestosPublicos/Presupuestosvotados/

Los presupuestos de la gestión Saca reducen porcentualmente el gasto de la administración central y su mayor partida se dedicó al financiamiento del plan 2021. En términos de la inversión en el nivel preuniversitario, la administración Saca destinó casi los mismos porcentajes en términos del presupuesto del MINED para financiar la Educación Parvularia, Básica y Media (69\%); sin embargo, en esta partida presupuestaria el dato que más llama la atención es la inclusión de entidades tales como el Instituto Salvadoreño para el desarrollo de la Niñez y la Adolescencia (ISNA), La Dirección Nacional de Juventud (hoy INJUVE) y Canal 10 de televisión que utilizaron casi un $4 \%$ del presupuesto del MINED en ese año. Además resalta el crecimiento de la partida destinada a financiar a fundaciones. Todo eso y unido al presupuesto destinado a Cultura sumó casi un 7.8\% del presupuesto del MINED.

En lo que respecta a remuneraciones, este se mantuvo en números similares a la gestión Flores con un 57\% del presupuesto del MINED y nuevamente el salario docente tuvo la mayor participación con una cifra un poco menor al 34\% del presupuesto del MINED.

A continuación se presenta el último presupuesto del MINED de la gestión Funes. 


\section{Cuadro n. ${ }^{\circ} 3$}

PRESUPUESTO VOTADO MINED 2014. ADMINISTRACIÓN FUNES (2009-2014). Datos en dólares de los Estados Unidos de América.

\begin{tabular}{|c|c|c|c|c|}
\hline & Partida presupuestaria & Cantidad & \multicolumn{2}{|c|}{$\%$} \\
\hline \multirow{8}{*}{$\begin{array}{l}\text { Administración } \\
\text { Central }\end{array}$} & Dirección y administración & $\$ 29,069,225$ & $3.28 \%$ & \multirow[t]{8}{*}{$8.73 \%$} \\
\hline & Desarrollo de la Educación & $\$ 16,873,770$ & $1.91 \%$ & \\
\hline & Gastos imprevistos & $\$ 1,489,095$ & $0.17 \%$ & \\
\hline & Caja Mutual & $\$ 1,051,220$ & $0.12 \%$ & \\
\hline & $\begin{array}{c}\text { Proyectos de inversión } \\
\text { (infraestructura) }\end{array}$ & $\$ 13,211,115$ & $1.49 \%$ & \\
\hline & Escuela Inclusiva TP/T. Progreso & $\$ 10,901,570$ & $1.23 \%$ & \\
\hline & Ciencia y Tecnología & $\$ 4,096,140$ & $0.46 \%$ & \\
\hline & CONACYT & $\$ 600,000$ & $0.07 \%$ & \\
\hline \multirow{3}{*}{$\begin{array}{l}\text { Educación Pre- } \\
\text { Universitaria }\end{array}$} & Educación Inicial/Parvularia & $\$ 64,797,855$ & $7.32 \%$ & \multirow[t]{3}{*}{$78.90 \%$} \\
\hline & Educación Básica & $\$ 551,891,305$ & $62.37 \%$ & \\
\hline & Educación Media & $\$ 81,492,925$ & $9.21 \%$ & \\
\hline \multirow{5}{*}{$\begin{array}{c}\text { Educación Superior } \\
\text { Pública }\end{array}$} & UES & $\$ 64,661,280$ & $7.31 \%$ & \multirow[t]{5}{*}{$7.42 \%$} \\
\hline & UES (BECAS) & $\$ 205,715$ & $0.02 \%$ & \\
\hline & UES (Morazán) & $\$ 500,000$ & $0.06 \%$ & \\
\hline & UES (Chalatenango) & $\$ 38,000$ & $0.00 \%$ & \\
\hline & Programa Jóvenes Talento & $\$ 300,000$ & $0.03 \%$ & \\
\hline \multirow[t]{5}{*}{ Otros } & $\begin{array}{c}\text { Subsidios instituciones privadas } \\
\text { (Fundaciones, EJA) }\end{array}$ & $\$ 19,911,150$ & $2.25 \%$ & \multirow[t]{4}{*}{$4.94 \%$} \\
\hline & Otras entidades & $\$ 151,605$ & $0.02 \%$ & \\
\hline & ISNA & $\$ 17,284,035$ & $1.95 \%$ & \\
\hline & CONNA & $\$ 6,400,865$ & $0.72 \%$ & \\
\hline & Total & $\$ 884,926,870$ & $100 \%$ & $100 \%$ \\
\hline
\end{tabular}

Fuente: Elaboración propia. Datos tomados del Portal de Transparencia del Ministerio de Hacienda (MH) de El Salvador. Disponible en: http:/www.transparenciafiscal.gob.sv/ptf/es/ PresupuestosPublicos/Presupuestosvotados/

El presupuesto del MINED en esta gestión presenta cambios significativos en algunas áreas. Por ejemplo, el dato de la Administración Central pasó de casi un $15 \%$ de las gestiones anteriores a un 9\% aproximadamente. Esto puede deberse a que los montos de inversión en los programas insignias como el Vaso de Leche, útiles, zapatos e uniformes para los estudiantes se trasladó al presupuesto de Educación Básica (que aumentó cerca del 10\% en comparación a las administraciones anteriores). Desaparece del presupuesto del MINED las partidas 
destinadas a Canal 10 y a la rama cultural que fueron adscritas a Secretarías de la Presidencia de la República, pero aparece la partida del Consejo Nacional de la Niñez y la Adolescencia (CONNA) y se mantiene el financiamiento del ISNA y de fundaciones casi con los mismos porcentajes respecto al presupuesto MINED 2009. Por lo que los gastos que se podrían considerar fuera de las funciones del MINED rondarían un 5\% en el año 2014.

La partida de remuneraciones del MINED sufre un aumento considerable respecto a las administraciones anteriores, que no superaban el 54\% del Presupuesto del MINED, a un 66\% en esta administración y la partida de salarios docentes pasó del 34\% en 2009 a un $42 \%$ en 2014. Este aumento de la partida de salarios puede tener su explicación a que los contratos de salarios del programa EDUCO pasaron a ley de salarios.

A continuación se presenta el presupuesto de la gestión de Sánchez Cerén.

\section{Cuadro n. ${ }^{\circ} 4$}

PRESUPUESTO VOTADO MINED 2018. ADMINISTRACIÓN CERÉN (2014-2019). Valores en dólares de los Estados Unidos de América.

\begin{tabular}{|c|c|c|c|c|}
\hline & Presupuesto MINED 2018 & Cantidad & \multicolumn{2}{|c|}{$\%$} \\
\hline \multirow{8}{*}{$\begin{array}{l}\text { Administración } \\
\text { Central }\end{array}$} & Dirección y administración & $\$ 30,254,515$ & $3.22 \%$ & \multirow[t]{8}{*}{$18.75 \%$} \\
\hline & Gestión Educativa & $\$ 19,579,905$ & $2.08 \%$ & \\
\hline & Ciencia y tecnología & $\$ 6,901,162$ & $0.73 \%$ & \\
\hline & Caja Mutual & $\$ 1,051,220$ & $0.11 \%$ & \\
\hline & Mejoramiento de la Calidad & $\$ 4,514,615$ & $0.48 \%$ & \\
\hline & Programas de Inversión & $\$ 6,539,650$ & $0.70 \%$ & \\
\hline & CONACYT & $\$ 1,234,715$ & $0.13 \%$ & \\
\hline & Programas de desarrollo & $\$ 106,215,810$ & $11.29 \%$ & \\
\hline \multirow{3}{*}{$\begin{array}{c}\text { Educación Pre- } \\
\text { universitaria }\end{array}$} & Educación Inicial/Parvularia & $\$ 65,386,765$ & $6.95 \%$ & \multirow[t]{3}{*}{$68.09 \%$} \\
\hline & Educación Básica & $\$ 488,384,506$ & $51.93 \%$ & \\
\hline & Educación Media & $\$ 86,559,045$ & $9.20 \%$ & \\
\hline \multirow{6}{*}{$\begin{array}{c}\text { Educación Superior } \\
\text { Pública }\end{array}$} & UES & $\$ 72,054,658$ & $7.66 \%$ & \multirow[t]{6}{*}{$8.34 \%$} \\
\hline & UES (BECAS) & $\$ 205,715$ & $0.02 \%$ & \\
\hline & Programa Jóvenes Talento & $\$ 600,000$ & $0.06 \%$ & \\
\hline & UES (Morazán) & $\$ 488,025$ & $0.05 \%$ & \\
\hline & UES (Chalatenango) & $\$ 38,000$ & $0.00 \%$ & \\
\hline & U en Línea & $\$ 5,000,000$ & $0.53 \%$ & \\
\hline
\end{tabular}




\begin{tabular}{|c|c|c|c|c|}
\hline & Presupuesto MINED 2009 & Cantidad & \multicolumn{2}{c|}{$\%$} \\
\hline \multirow{3}{*}{ Otro } & ISNA & $\$ 20,197,800$ & $2.15 \%$ & $4.83 \%$ \\
\cline { 2 - 5 } & CONNA & $\$ 6,443,198$ & $0.69 \%$ & $2.00 \%$ \\
\cline { 2 - 5 } & Subsidios instituciones privadas & $\$ 18,778,520$ & $\mathbf{1 0 0 . 0 \%}$ & $\mathbf{1 0 0 . 0} \%$ \\
\hline
\end{tabular}

Fuente: Elaboración propia. Datos tomados del Portal de Transparencia del Ministerio de Hacienda (MH) de El Salvador. Disponible en: http:/www.transparenciafiscal.gob.sv/ptf/es/ PresupuestosPublicos/Presupuestosvotados/

El cuarto presupuesto votado de la administración Sánchez Cerén se parece mucho más en términos de distribución de los gastos a los presentados por Flores y Saca. La partida de programas de desarrollo incluye todos los gastos relacionados a los programas sociales de la administración Funes con casi un $11 \%$ del presupuesto MINED de 2018. En porcentajes del presupuesto del MINED se mantienen los valores de inversión en Educación Inicial y Básica, la Educación Media aumentó un punto porcentual al igual que el presupuesto destinado a la Universidad de El Salvador en el cual el programa "Jóvenes Talento" duplicó su presupuesto en esta nueva gestión. El porcentaje de participación del ISNA, CONNA y el subsidio a instituciones privadas se mantienen alrededor de un 5\% respecto al presupuesto del MINED.

Los datos de remuneración en general y salarios docentes respecto al presupuesto MINED se mantienen en el $62 \%$ y $42 \%$ respectivamente.

Con lo anterior se puede concluir que en todos los quinquenios existieron partidas

7 Boletín Estadístico 33 MINED 2016, tomado el día 30 de abril de 2018. Disponible en: http://www.mined.gob.sv/EstadisticaWeb/ boletines/2016/Boletin_Estad\%C3\%ADstico_N_33_Censo_ Escolar_2016.pdf presupuestarias fuera de los fines y objetivos del MINED y que estas rondaron entre el 5\% y el 8\% del presupuesto total. Esto no quiere decir que sean ilegales o que no deban recibir algún tipo de retribución del Estado, en absoluto, (muchas de esas fundaciones, ONG o universidades prestan servicios diversos al MINED aunque no se esclarece por qué reciben dichos fondos), pero sí se puede cuestionar que en algunos periodos el presupuesto del MINED haya financiado a la Federación de Fútbol o a Canal 10 o a instituciones ligadas a la beneficencia y a la protección de menores como sucede en los últimos años.

¿Qué otros análisis se puede hacer de los datos anteriores? En general, se observa que en la mayoría de los presupuestos, la mayor tajada se la lleva la Educación Básica y la inversión en Bachillerato es casi cinco veces menor a ella, por esa razón no es de extrañar que según datos del MINED sólo un 40\% de los jóvenes salvadoreños tienen acceso a la Educación Media, ${ }^{7}$ sobre la inversión en Educación Superior, los datos reflejan que, según el PIB, la única universidad pública del país nunca superó el 0.4\%. Además de eso es bueno discutir sobre el peso de las remuneraciones en el presupuesto del MINED. En los últimos 
años se ha discutido mucho sobre el "aumento de la grasa del Estado" si vemos los datos, este pasó de representar un 54\% del presupuesto total del Ministerio en 2009 a un 62\% en 2018 y casi dos tercios de ese porcentaje se debe al salario docente (42\% del presupuesto ministerial) lo que deja poco margen para inversión concreta en educación.

Por último, estos datos también reflejan un dato interesante relacionado a la temática de la sección anterior y es: ¿cuánto se endeuda el Estado para inversión en Educación? Pese a que El Salvador, según datos del BCR, cuenta con una deuda que ronda entre el $60 \%$ y el $75 \%$ del PIB esta no destaca por ser inversión en educación ya que según estos presupuestos la fuente principal del financiamiento del MINED es el fondo general con casi el 90\%95\% y muy pocas veces fue financiado por préstamos o donaciones (VER ANEXO).

Ahora bien, ¿cómo se financia la educación en países de la región? Para responder esta pregunta se trae, a manera de ejemplo, los datos de inversión general en la República de Costa Rica.

\section{Inversión en educación en costa rica}

Mucho se ha hablado en los últimos años de la inversión pública en educación que hace Costa Rica. Medios de comunicación, economistas, políticos y hasta estudiosos del

8 Tomado de Banco Central de Costa Rica (BCCR). Consultado el día 30/04/2018. Disponible en https://gee.bccr.fi.cr/indicadoreseconomicos/Cuadros/frmVerCatCuadro.aspx?CodCuadro=2980\&Idioma=1\&FecInicial=2004/12/31\&FecFinal=2016/12/31.

9 Tomado del Ministerio de Hacienda de Costa Rica (BCCR). Consultado el día 30/04/2018. Disponible en http://www.hacienda.go.cr/ contenido/424-leyes-de-presupuestos. tema han resaltado la visión de Estado que ha hecho invertir al país centroamericano, en porcentajes del PIB, mucho más que otras potencias mundiales. Sin embargo, ese ejercicio de comparación sin tomar en cuenta el contexto histórico, social, político, educativo y económico lleva a interpretaciones alejadas de la realidad. Es por ello que se aclara que la presentación de los siguientes datos no busca generar la impresión de decir que país es mejor o peor en cuanto a la inversión pública en educación, ni tampoco es objetivo de este artículo traer todos esos elementos a la discusión ya que eso implaría un esfuerzo mucho mayor que requeriría de más espacio, pero sí se busca traer algunos datos y cifras a modo contribuir a una discusión un poco más amplia de cómo enfrentar el estancamiento de la inversión pública en educación en El Salvador.

Para ello, se presenta en el cuadro siguiente los datos brutos del PIB, PGN, el Presupuesto del Ministerio de Educación Pública (PMEP) de Costa Rica y, además, presento los datos de la deuda contraída para financiar el PMEP y el PGN de los años 2005, 2010 y 2015. Los datos a continuación fueron tomados del sitio web del Banco Central de Reserva ${ }^{8}$ y del Ministerio de Hacienda de Costa Rica. ${ }^{9}$ 
Tabla n. ${ }^{\circ} 10$

Inversión en educación en Costa Rica: años 2005, 2010 y 2015. en millones de colones costarricenes

\begin{tabular}{|c|c|c|c|}
\hline Indicador & 2005 & 2010 & 2015 \\
\hline PIB & $\$ 9532,875.01$ & $\$ 19596,936.68$ & $\$ 29281,361.82$ \\
\hline PGN & $\$ 2309,634.76$ & $\$ 4567,484.00$ & $\$ 7959,345.53$ \\
\hline PMEP & $\$ 471,229.17$ & $\$ 1266,077.00$ & $\$ 2201,008.53$ \\
\hline Fin. Deuda MEP & $\$ 6,556.30$ & $\$ 172,425.56$ & $\$ 1559,854.53$ \\
\hline Deuda PGN & $\$ 1092,710.61$ & $\$ 1900,562.90$ & $\$ 3758,752.53$ \\
\hline
\end{tabular}

Fuente: elaboración propia, datos de Banco Central de Costa Rica y del Ministerio de Hacienda de Costa Rica.

Tomando en cuenta los datos anteriores los porcentajes de inversión pública en educación (\% MEP/PIB), el porcentaje de financiamiento del PMEP con deuda (\% F. Deuda/MEP) y el porcentaje de la deuda para financiar al MEP y al PGN, según el PIB, son los siguientes:

\section{Tabla n..$^{\circ} 11$}

Inversión en educación en Costa Rica: años 2005, 2010 y 2015.

\begin{tabular}{|c|c|c|c|}
\hline Indicadores & $\mathbf{2 0 0 5}$ & $\mathbf{2 0 1 0}$ & $\mathbf{2 0 1 5}$ \\
\hline \% MEP/PIB & $4.94 \%$ & $6.46 \%$ & $7.52 \%$ \\
\hline$\%$ MEP/PGN & $20.40 \%$ & $27.72 \%$ & $27.65 \%$ \\
\hline \% F. Deuda/MEP & $1.39 \%$ & $13.62 \%$ & $70.87 \%$ \\
\hline \% F. Deuda MEP/PIB & $0.07 \%$ & $0.88 \%$ & $5.33 \%$ \\
\hline$\%$ F. Deuda PGN/PIB & $11.5 \%$ & $9.7 \%$ & $12.8 \%$ \\
\hline \% F. Deuda/PGN & $47.31 \%$ & $41.61 \%$ & $47.22 \%$ \\
\hline
\end{tabular}

Fuente: Nota: Elaboración propia.

Al analizar los datos del presupuesto del Ministerio de Educación Pública de Costa Rica (MEP) en porcentajes del PIB y del PGN resaltan muchas cosas, de las cuales se destacan los siguientes: el presupuesto del MEP ha subido cerca de 2.5\% puntos del PIB de 2005 a 2015. El presupuesto del MEP pasó de representar el 20\% del presupuesto del PGN en 2005 a un 27.7\% el año 2015. Estos dos datos reflejan, sin duda, el esfuerzo del Estado costarricense por invertir en educación y son los que han sido ampliamente citados en los medios de comunicación, pero 
¿Cómo se explican esos números? Los dos últimos datos reflejan que cerca de la mitad del PGN se ha financiado con deuda y que cada año esa deuda ha representado cerca del $10 \%$ de su PIB. Costa Rica pasó de tener un 24\% de deuda respecto al PIB en 2008 a representar cerca de un $50 \%$ respecto al PIB en $2016 .^{10}$

Luego, ¿qué argumentos se podrían aportar para explicar las diferencias de indicadores entre ambos países? Es claro que, como se dijo anteriormente, faltan otros datos para explicar estos números. Como por ejemplo datos de crecimiento económico, niveles de endeudamiento entre países, indicadores sociales (seguridad social, pensiones, desempleo, tasas delincuenciales, demografía, etc.), indicadores educativos (tasa de cobertura, programas de desarrollo, salarios docentes y personal técnico, etc.) y otros más para poder empezar la discusión y comparar esos datos de ambos países. La complejidad de todos esos elementos hace que comparar uno sólo indicador, como sucede cuando se compara la inversión en educación según el PIB entre países, sería como diagnosticar a dos pacientes de la misma enfermedad sólo por lo que marca el termómetro. Ese ejercicio de simplificación debe ser olvidado y los estudiosos, especialmente, deben proveer otros elementos para hacer más amplia esta discusión.

En la siguiente y última sección se buscará hacer unas reflexiones finales a modo de conclusión del tema.

10 Tomado de: E1 Financiero. Consultado el día 30/04/18. Disponible en: https://www.elfinancierocr.com/economia-y-politica/deuda-de-costa-rica-sera-del-50-del-pib-al-2016-cuanto-registranotros-paises/EP4IUT2KVRGVTNYREVRUTEM43Y/story/

\section{Reflexiones finales}

En este artículo se buscó discutir acerca del financiamiento de la educación en El Salvador en el período que va del año 2000 al año 2018, a la luz de los resultados del nuevo Sistema de Cuentas Nacionales (SCN) publicado por el BCR en marzo de 2018. Para ello se presentaron los datos del PIB, del PGN y del presupuesto del MINED por quinquenio presidencial comenzando por la gestión Flores (1999-2004), Saca (2004-2009), Funes (2009-2014) y la gestión actual de Salvador Sánchez Cerén que comenzó en 2014 y finalizará en 2019.

Los datos arrojaron que, a diferencia de los cálculos que se hacían con el anterior SCN, el presupuesto del MINED de El Salvador ya tuvo dos años en los cuales alcanzó una cifra igual o mayor al 4\% según el PIB. En términos brutos el crecimiento del presupuesto en estos años ha más que el doble, pasando de 385 millones en el año 2000 a 940 millones en el 2018. Sin embargo, estos datos en relación al PIB solamente pasaron del 3.49\% en el 2000 a $3.95 \%$ en 2018 , cerca de $0.5 \%$ en 18 años, cifra evidentemente insuficientes para las necesidades reales del país tal como fueron consignadas en el documento del Consejo Nacional de Educación de El Salvador (CONED) que estimaba el financiamiento del plan "El Salvador Educado” en más de 12,573 millones de dólares en una década (2016-2016) (MINED, 2016).

Luego de la presentación de esos datos, se procedió a desglosar con mayor detalle las partidas de gastos que constituyeron los presupuestos del MINED de los últimos años de las gestiones Flores (2004), Saca (2009), Funes (2014) y Cerén (2018). Los datos reflejaron que todos esos presupuestos 
tenían asignado al menos un 5\% de su total a instituciones que estaban alejadas de alcanzar los fines y objetivos de la educación del país. Se explicó que esto no era ilegal, ni se cuestionaba esa asignación, pero sí se cuestionaba que esos montos se incluyesen en el presupuesto del MINED ya que podría darse el caso que otras gestiones incluyesen otros gastos a modo de "inflar" la cifra del presupuesto MINED.

Además, este artículo trajo a discusión algunos datos del financiamiento de la educación de Costa Rica. Se explicó que esto no tenía como objetivo hacer una comparación de indicadores simplemente $\mathrm{y}$ sí tenía como objetivo alertar a los investigadores, docentes, economistas y generadores de opinión a no caer en la simplificación del análisis al tomar únicamente el valor final sin tomar en cuenta el contexto en el cual suceden.

Entonces, ¿qué conclusiones se podrían plantear sobre lo discutido anteriormente? Primero creo que es conveniente señalar las dificultades que tiene medir el "éxito de una gestión ministerial", de acuerdo al porcentaje del PIB que invierte en educación. Algunos podrían tomar estos datos y decir que "los últimos gobiernos han aumentado la inversión en educación" algo que es discutible ya que presumir el aumento de menos de $0.5 \%$ del PIB en diez años no es algo digno de celebrar. A ese ritmo se podría alcanzar el "soñado 6\% PIB en educación” en 40 años; nada prometedor tomando en cuenta las reales necesidades del sistema.

Por último, se presentan unas inquietudes a modo de generar debate en torno a la temática de este artículo: ¿Alcanzar el 6\% del PIB en educación es suficiente para las necesidades del país?, ¿Qué indicadores económicos inciden en el aumento de los indicadores de inversión en educación?, ¿Es posible invertir el 6\% del PIB en educación con una carga tributaria muy baja (menor al 20\%)?, ¿Qué tipo de indicador representaría mejor la comparación entre dos países con cargas tributarias diferentes sobre su inversión en educación?, ¿Qué “gastos” podrían considerarse dentro de un presupuesto de educación?, ¿Qué cuidados requiere hacer una clasificación de los países según su porcentaje de inversión en educación en términos del PIB? ¿Se puede o debe hacer esa clasificación sin considerar su proceso histórico y contexto social, político, económico y educativo? Y para finalizar ila inversión en educación debe estar en términos del PIB o en términos de las reales necesidades del país?

\section{Referencias bibliográficas}

Ministerio de Educación (2000). Desafíos de la Educación en el Nuevo Milenio. San Salvador: Autor.

MinisteriodeEducación(2002). Memoriadelabores 2001-2002. San Salvador: Autor. Recuperado de: http://www.mined.gob.sv/jdownloads/ Memorias\%20de\%20Labores/2001\%20-\%20 2002\%20Memoria_2002.pdf.

Ministerio de Educación (2005). Plan Nacional de Educación 2021. San Salvador: Autor.

Ministerio de Hacienda (2010). Informe de la gestión financiera del Estado, Ejercicio Fiscal 2009. San Salvador: Autor. Disponible en: http:// www.transparenciafiscal.gob.sv/downloads/pdf/ DC4457_CAPITULO_II_2009.pdf.

Ministerio de Educación (2016). Plan El Salvador Educado. San Salvador: Autor. 


\section{Anexos}

Anexo 1: presupuesto del Ministerio de Educación (MINED) de El Salvador por fuente de financiamiento años 2004, 2009, 2014 y 2018

\begin{tabular}{|c|c|c|}
\hline Fuente de Financiamiento & Monto & \% del P. MINED \\
\hline Presupuesto General & $\$ 429,999,280.00$ & $91.4 \%$ \\
\hline Préstamo & $\$ 39,080,530.00$ & $8.3 \%$ \\
\hline Donación & $\$ 1,417,980.00$ & $0.3 \%$ \\
\hline Total & $\$ \mathbf{4 7 0 , 4 9 7 , 7 9 0 . 0 0}$ & $\mathbf{1 0 0 . 0 \%}$ \\
\hline
\end{tabular}

Fuente: Elaboración propia. Datos tomados del Portal de Transparencia del Ministerio de Hacienda (MH) de El Salvador. Disponible en: http:/www.transparenciafiscal.gob.sv/ptf/es/ PresupuestosPublicos/Presupuestosvotados/

Fuente de financiamiento del presupuesto MINED 2009.

\begin{tabular}{|c|c|c|}
\hline Fuente de Financiamiento & Monto & \% del P. MINED \\
\hline Presupuesto General & $\$ 697,932,140$ & $99.3 \%$ \\
\hline Préstamo & $\$-$ & $0.0 \%$ \\
\hline Donación & $\$ 4,942,565$ & $0.7 \%$ \\
\hline Total & $\mathbf{\$ 7 0 2 , 8 7 4 , 7 0 5}$ & $\mathbf{1 0 0 . 0 \%}$ \\
\hline
\end{tabular}

Fuente: Elaboración propia. Datos tomados del Portal de Transparencia del Ministerio de Hacienda (MH) de El Salvador. Disponible en: http://www.transparenciafiscal.gob.sv/ptf/es/ PresupuestosPublicos/Presupuestosvotados/

\section{Fuente de financiamiento del presupuesto MINED 2014.}

\begin{tabular}{|c|c|c|}
\hline Fuente de Financiamiento & Monto & \% del P. MINED \\
\hline Presupuesto General & $\$ 866814,385$ & $98.0 \%$ \\
\hline Préstamo & $\$ 15684,900$ & $1.8 \%$ \\
\hline Donación & $\$ 2427,585$ & $0.3 \%$ \\
\hline Total & $\$ \mathbf{8 8 4 9 2 6 , 8 7 0}$ & $\mathbf{1 0 0 . 0 \%}$ \\
\hline
\end{tabular}

Fuente: Elaboración propia. Datos tomados del Portal de Transparencia del Ministerio de Hacienda (MH) de El Salvador. Disponible en: http:/www.transparenciafiscal.gob.sv/ptf/es/ PresupuestosPublicos/Presupuestosvotados/ 
Fuente de financiamiento del presupuesto MINED 2018.

\begin{tabular}{|c|c|c|}
\hline Fuente de Financiamiento & Monto & \% del P. MINED \\
\hline Fuente de Financiamiento & Monto & \% del P. MINED \\
\hline Presupuesto General & $\$ 937913,209$ & $99.73 \%$ \\
\hline Préstamo & $\$ 2514,615$ & $0.27 \%$ \\
\hline Donación & $\$-$ & $0.00 \%$ \\
\hline Total & $\mathbf{\$ 9 4 0 4 2 7 , 8 2 4}$ & $\mathbf{1 0 0 \%}$ \\
\hline
\end{tabular}

Fuente: Elaboración propia. Datos tomados del Portal de Transparencia del Ministerio de Hacienda (MH) de El Salvador. Disponible en: http:/www.transparenciafiscal.gob.sv/ptf/es/ PresupuestosPublicos/Presupuestosvotados/

\section{Anexo 2: remuneraciones del Ministerio de Educación}

Años 2004, 2009, 2014 y 2018

\section{Remuneraciones MINED, en USD, y porcentajes según presupuesto MINED.}

\begin{tabular}{|c|c|c|}
\multicolumn{2}{c}{ Año 2004} \\
\hline Rubro & Monto & \% Presupuesto del MINED \\
\hline Remuneraciones & $\$ 276406,195.00$ & $58.7 \%$ \\
\hline Salario Docente & $\$ 173359,005.00$ & $36.8 \%$ \\
\hline
\end{tabular}

Fuente: Elaboración propia, con base en presupuesto MINED 2004. Disponible en: http://www. transparenciafiscal.gob.sv/ptf/es/PresupuestosPublicos/Presupuestosvotados/

\section{Remuneraciones MINED, en USD, y porcentajes según presupuesto MINED.}

Año 2009

\begin{tabular}{|c|c|c|}
\hline Rubro & Monto & \% Presupuesto del MINED \\
\hline Remuneraciones & $\$ 396847,150.00$ & $56.5 \%$ \\
\hline Salario Docente & $\$ 235705,915.00$ & $33.5 \%$ \\
\hline
\end{tabular}

Fuente: Elaboración propia, con base en presupuesto MINED 2009. Disponible en: http://www. transparenciafiscal.gob.sv/ptf/es/PresupuestosPublicos/Presupuestosvotados/ 


\section{Remuneraciones MINED, en USD, y porcentajes según presupuesto MINED.}

Año 2014

\begin{tabular}{|c|c|c|}
\hline Rubro & Monto & \% Presupuesto del MINED \\
\hline Remuneraciones & $\$ 580958,690.00$ & $65.7 \%$ \\
\hline Salario Docente & $\$ 371808,370.00$ & $42.0 \%$ \\
\hline
\end{tabular}

Fuente: Elaboración propia, con base en presupuesto MINED 2014. Disponible en: http://www. transparenciafiscal.gob.sv/ptf/es/PresupuestosPublicos/Presupuestosvotados

\section{Remuneraciones MINED, en USD, y porcentajes según presupuesto mined.}

\begin{tabular}{|c|c|c|}
\multicolumn{2}{|c|}{ Año 2018} \\
\hline Rubro & Monto & \% Presupuesto del MINED \\
\hline Remuneraciones & $\$ 636790,290.00$ & $67.7 \%$ \\
\hline Salario Docente & $\$ 398104,610.00$ & $42.3 \%$ \\
\hline
\end{tabular}

Fuente: Elaboración propia, con base en presupuesto MINED 2018. Disponible en: http://www. transparenciafiscal.gob.sv/ptf/es/PresupuestosPublicos/Presupuestosvotados/

Anexo 3: Remuneraciones del Ministerio de Educación, por tipo de personal años 2004, 2009, 2014 y 2018

\begin{tabular}{|c|c|c|c|c|c|}
\hline \multicolumn{3}{|c|}{$\begin{array}{c}\text { Remuneraciones, en USS, y cantidad de personal } \\
\text { MINED año } 2004 .\end{array}$} & \multicolumn{3}{|c|}{$\begin{array}{c}\text { Remuneraciones, en USS, y cantidad de personal } \\
\text { MINED año } 2014 .\end{array}$} \\
\hline Personal & Monto & Personal & Personal & Monto & Personal \\
\hline De Gobierno & $\$ 91,695.00$ & 3 & De Gobierno & $\$ 83,220.00$ & 3 \\
\hline Ejecutivo & $\$ 766,840.00$ & 30 & Ejecutivo & $\$ 1721,080.00$ & 64 \\
\hline Técnico & $\$ 9969,780.00$ & 1507 & Técnico & $\$ 15933,205.00$ & 1251 \\
\hline Docente & $\$ 173359,005.00$ & 31313 & Docente & $\$ 371808,370.00$ & 43562 \\
\hline Administración & $\$ 10652,650.00$ & 1740 & Administración & $\$ 15813,280.00$ & 1665 \\
\hline De obra & $\$ 257,475.00$ & 70 & De obra & $\$ 152,810.00$ & 22 \\
\hline De Servicio & $\$ 3851,210.00$ & 1079 & De Servicio & $\$ 3992,345.00$ & 651 \\
\hline Total & $\$ 198948,655.00$ & 35742 & Total & $\$ 409504,310.00$ & 47218 \\
\hline \multicolumn{3}{|c|}{$\begin{array}{l}\text { Fuente: elaboración propia, con base en presupuesto } \\
\text { MINED } 2004 .\end{array}$} & \multicolumn{3}{|c|}{$\begin{array}{l}\text { Fuente: elaboración propia, con base en presupuesto } \\
\text { MINED } 2014 .\end{array}$} \\
\hline
\end{tabular}




\begin{tabular}{|c|c|c|c|c|c|}
\hline \multicolumn{3}{|c|}{$\begin{array}{c}\text { Remuneraciones, en USS, y cantidad de personal } \\
\text { MINED año } 2009 .\end{array}$} & \multicolumn{3}{|c|}{$\begin{array}{c}\text { Remuneraciones, en USS, y cantidad de personal } \\
\text { MINED año } 2018 .\end{array}$} \\
\hline Personal & Monto & Personal & Personal & Monto & Personal \\
\hline De Gobierno & $\$ 142,190.00$ & 4 & De Gobierno & $\$ 83,220.00$ & 3 \\
\hline Ejecutivo & $\$ 747,460.00$ & 39 & Ejecutivo & $\$ 2620,915.00$ & 66 \\
\hline Técnico & $\$ 19467,235.00$ & 1752 & Técnico & $\$ 9323,445.00$ & 1251 \\
\hline Docente & $\$ 235705,915.00$ & 33890 & Docente & $\$ 398104,610.00$ & 43562 \\
\hline Administración & $\$ 15709,375.00$ & 1859 & Administración & $\$ 18578,300.00$ & 1666 \\
\hline De obra & $\$ 296,895.00$ & 54 & De obra & $\$ 173,980.00$ & 22 \\
\hline De Servicio & $\$ 4475,610.00$ & 773 & De Servicio & $\$ 4517,410.00$ & 651 \\
\hline Total & $\$ 276544,680.00$ & 38371 & Total & $\$ 433401,880.00$ & 47221 \\
\hline \multicolumn{3}{|c|}{$\begin{array}{l}\text { Fuente: elaboración propia, con base en presupuesto } \\
\text { MINED } 2009 .\end{array}$} & \multicolumn{3}{|c|}{$\begin{array}{l}\text { Fuente: elaboración propia, con base en presupuesto } \\
\text { MINED } 2018 .\end{array}$} \\
\hline
\end{tabular}

